\title{
Relationships among Cortical Glutathione Levels, Brain Amyloidosis, and Memory in Healthy Older Adults Investigated In Vivo with ${ }^{1} \mathrm{H}-\mathrm{MRS}$ and Pittsburgh Compound-B PET
}

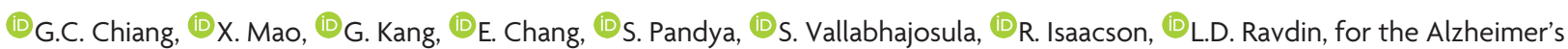
Disease Neuroimaging Initiative, and DD.C. Shungu

\begin{abstract}
BACKGROUND AND PURPOSE: Oxidative stress has been implicated as an important pathologic mechanism in the development of Alzheimer disease. The purpose of this study was to assess whether glutathione levels, detected noninvasively with proton MR spectroscopy, are associated with brain amyloidosis and memory in a community-dwelling cohort of healthy older adults.

MATERIALS AND METHODS: Fifteen cognitively healthy subjects were prospectively enrolled in this study. All subjects underwent ${ }^{1} \mathrm{H}-\mathrm{MR}$ spectroscopy of glutathione, a positron-emission tomography scan with an amyloid tracer, and neuropsychological testing by using the Repeatable Battery for the Assessment of Neuropsychological Status. Associations among glutathione levels, brain amyloidosis, and memory were assessed by using multivariate regression models.
\end{abstract}

RESULTS: Lower glutathione levels were associated with greater brain amyloidosis in the temporal $(P=.03)$ and parietal $(P=.05)$ regions, adjusted for apolipoprotein E \&4 carrier status. There were no significant associations between glutathione levels and cognitive scores.

CONCLUSIONS: This study found an association between cortical glutathione levels and brain amyloidosis in healthy older adults, suggesting a potential role for ${ }^{1} \mathrm{H}-\mathrm{MR}$ spectroscopy measures of glutathione as a noninvasive biomarker of early Alzheimer disease pathogenesis.

ABBREVIATIONS: $A D=$ Alzheimer disease; $A D N I=$ Alzheimer's Disease Neuroimaging Initiative; $A$ POE = apolipoprotein E; GSH = glutathione; PiB = Pittsburgh compound-B; RBANS = Repeatable Battery for the Assessment of Neuropsychological Status

A lzheimer disease $(\mathrm{AD})$, a devastating neurodegenerative disorder afflicting $>11 \%$ of individuals older than 65 years of age, ${ }^{1}$ is currently the sixth leading cause of death in the United States. Various forms of therapy have failed to show clinical benefit in individuals with $\mathrm{AD} .^{2}$ In the absence of disease-modifying pharmacotherapy for $\mathrm{AD}$, identifying and potentially targeting early pathologic processes that may lead to the development of $\mathrm{AD}$ are essential in developing prevention strategies.

Oxidative stress, defined as excessive production of free radicals relative to total tissue antioxidant reserves, has emerged from in vitro and preclinical studies as a key pathologic process in the

Received October 17, 2016; accepted after revision January 19, 2017.

From the Departments of Radiology (G.C.C., X.M., G.K., E.C., S.P., S.V., D.C.S.) and Neurology (R.I., L.D.R.), Weill Cornell Medical College, NewYork-Presbyterian Hospital, New York, New York.

This work was supported by a National Institutes of Health National Center for Advancing Translational Sciences/CTSC grant (UL1 TR000457-06) and by NIH grant S10 OD021782.

Please address correspondence to Gloria C. Chiang, MD, Department of Radiology, Division of Neuroradiology, Weill Cornell Medical College, NewYork-Presbyterian Hospital, 525 East 68th St, Starr Pavilion, Box 141, New York, NY 10065; e-mail: gcc9004@med.cornell.edu

- Indicates open access to non-subscribers at www.ajnr.org

http://dx.doi.org/10.3174/ajnr.A5143 development of AD. ${ }^{3-8}$ In transgenic mouse models, depletion of the reduced form of the tripeptide thiol glutathione (GSH) - the most abundant intracellular antioxidant and free radical scavenger and a reliable marker of oxidative stress ${ }^{9}$ - has been reported to precede amyloid oligomerization and plaque formation, ${ }^{10,11}$ both pathologic hallmarks of AD. A self-propagating cycle of free radical formation, oxidative stress, and amyloid plaque formation has also been shown in vitro. ${ }^{12}$ Furthermore, it has been suggested that amyloid may have antioxidant properties, thereby serving as a compensatory mechanism in the presence of oxidative stress. ${ }^{13}$ However, the relationship between oxidative stress and amyloidosis in humans remains poorly understood, particularly early in the disease course when oxidative stress may serve as a potential target for disease-modifying interventions.

The primary aim of this study was therefore to assess the relationship between proton MR spectroscopy measures of GSH levels and brain amyloidosis, as assessed by positron-emission tomography with the amyloid tracer Pittsburgh compound-B (PiB), ${ }^{14}$ in a prospective cognitively healthy community cohort of elderly subjects. Secondarily, we aimed to assess the relationship between GSH levels and memory. Last, we investigated whether GSH levels were associated with potentially modifiable AD risk factors. 


\section{MATERIALS AND METHODS Subjects}

Fifteen cognitively healthy subjects, recruited through flyers posted in the community, newspaper advertisements, and ambulatory care clinics, were prospectively enrolled. All subjects gave written informed consent to participate in this study, which was approved by the institutional review board of our institution.

Inclusion criteria consisted of individuals between 55 and 75 years of age with intact ability to perform all routine activities of daily living, including living independently in the community. None of the subjects met the criteria for mild cognitive impairment or AD. Subjects were also excluded if they had comorbid medical conditions that could impact brain function, including major psychiatric disorders (ie, major depression, bipolar disorder, psychosis), brain tumors, prior strokes, significant traumatic brain injury (defined as requiring a visit to the emergency department or a hospital admission), seizure disorders, recent illicit drug use, alcohol abuse, and other major medical conditions, such as heart failure, recent myocardial infarction, renal failure, liver disease, chronic obstructive pulmonary disease, and malignancy.

\section{Clinical Data}

All subjects completed detailed questionnaires about their medical history and medical records were also examined. Clinical data collected included recent weight and height, cholesterol levels, blood pressure measurements, and the number of hours of exercise per week, because these factors have been reported to be associated with the risk for AD. ${ }^{15,16}$ Exercise was defined as physical activity more strenuous than daily routine activity. We also elicited a family history of dementia, because genetics could explain increased brain amyloidosis in otherwise cognitively healthy subjects. $^{17}$

\section{Cognitive Battery}

Cognitive testing was performed by a board-certified neuropsychologist (L.D.R.). Patients were first screened for depression and anxiety by using the Beck Depression Inventory-II ${ }^{18}$ and the Beck Anxiety Inventory. ${ }^{19}$ Immediate and delayed memory were assessed by using subscores of the Repeatable Battery for the Assessment of Neuropsychological Status (RBANS) based on tasks that involved recalling a list of words and a short story. ${ }^{20}$ Additional cognitive domains assessed included visuospatial and constructional function, assessed with figure copying and line orientation tasks; attention, assessed with digit span and coding tasks; and language, assessed with picture naming and semantic fluency tasks. The RBANS has been previously reported to have $90 \%$ accuracy for discriminating between cognitively healthy individuals and those with mild cognitive impairment. ${ }^{21}$

\section{Apolipoprotein E $\varepsilon 4$ Genotyping}

Blood samples were obtained from all subjects to isolate DNA for Apolipoprotein E (APOE) genotyping, which was performed by using polymerase chain reaction amplification, allele-specific primers, and identification of fragments on an agarose gel. $^{22}$
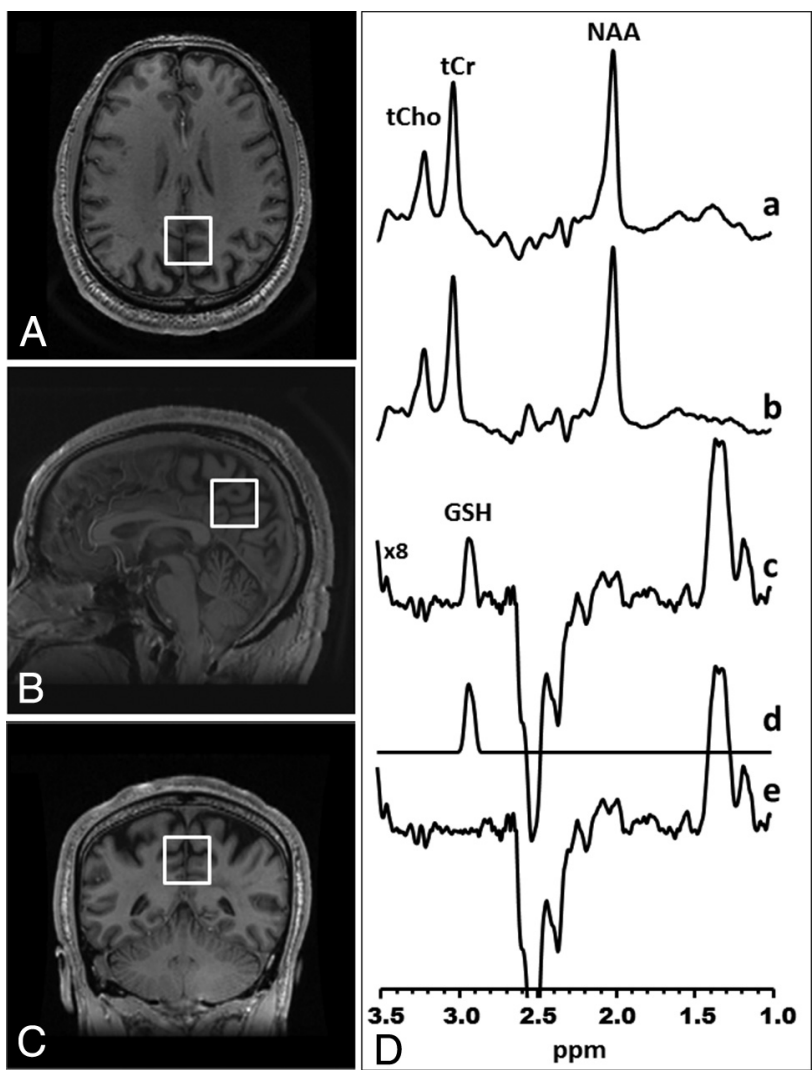

FIG 1. Glutathione detection in the medial parietal lobe with J-edited ${ }^{1} \mathrm{H}-\mathrm{MR}$ spectroscopy. Axial (A), sagittal (B), and coronal (C) MR images of a human brain, with depiction of the size, location, and angulation of the voxel of interest in the medial parietal lobe. $D$, Demonstration of in vivo human brain glutathione detection by ${ }^{1} \mathrm{H}-\mathrm{MR}$ spectroscopy: spectra $a$ and $b$, single-voxel subspectra acquired in 15 minutes with the editing pulse on and off and 290 (580 total) interleaved averages; spectrum $c$, difference between spectra $a$ and $b$, showing the edited brain GSH resonance at $2.98 \mathrm{ppm}$; spectrum $d$, model fitting of spectrum $c$ to obtain the GSH peak area; spectrum $e$, residual of the difference between spectra $c$ and $d$. tCho indicates total choline; $\mathrm{tCr}$, total creatine.

\section{MR Imaging and Spectroscopy Data Acquisition and Analysis}

All subjects underwent standardized structural MR imaging of the brain and single-voxel ${ }^{1} \mathrm{H}$-MR spectroscopy on a research-dedicated 3T MR imaging system (Excite HD; GE Healthcare, Milwaukee, Wisconsin) with an 8-channel phased array head coil. The MR imaging protocol consisted of a structural T1-weighted spoiled gradient-recalled echo volumetric scan for tissue segmentation and an axial fast fluid-attenuated inversion recovery scan to exclude focal pathology.

In vivo ${ }^{1} \mathrm{H}-\mathrm{MR}$ spectroscopy data were obtained from a $2.5 \times$ $2.5 \times 2.5 \mathrm{~cm}^{3}$ voxel prescribed in the medial parietal lobe to include the posterior cingulate gyrus and precuneus-a region chosen because multiple prior studies reported early involvement of these regions by $\mathrm{AD}$ due to their inclusion in the memory network..$^{23-26}$ The standard J-edited spin-echo difference method with $\mathrm{TE} / \mathrm{TR}=68 / 1500 \mathrm{~ms}$ was used to measure the levels of reduced GSH, as previously described ${ }^{27-30}$ and illustrated in Fig 1. Although it has been suggested that a TE of $120 \mathrm{~ms}$ is optimal for GSH detection by J-editing, ${ }^{31}$ we opted to use a TE of $68 \mathrm{~ms}$ because it yields a difference spectrum in which the coedited as- 
partyl $(\mathrm{CH} 2)$ resonances of NAA around $2.5 \mathrm{ppm}$ are inverted and clearly separated from the noninverted GSH resonance, facilitating spectral fitting (Fig 1). ${ }^{27,28}$

Briefly, a pair of frequency-selective inversion pulses was inserted into the standard point-resolved spectroscopy sequence method and was applied on alternate scans at the frequency of the GSH $\alpha$-cysteinyl resonance at $4.56 \mathrm{ppm}$ while avoiding excitation of oxidized GSH $\alpha$-cysteinyl at 3.28 ppm. ${ }^{32}$ This process resulted in 2 subspectra in which reduced GSH, but not oxidized GSH, was alternately inverted or not inverted. Subtracting these 2 subspectra yielded a ${ }^{1} \mathrm{H}$-MR spectrum consisting of only the edited GSH $\beta$-cysteinyl resonance at $2.98 \mathrm{ppm}$. A high test-retest reliability has been reported for detection of $\gamma$-aminobutyric acid with this MR spectroscopy technique on the same 3T GE Healthcare Excite HD instrument. ${ }^{33}$ Spectral data for this study were acquired in 15 minutes by using 290 interleaved excitations ( 580 total) with the editing pulses on or off. The area under the GSH resonance, which is proportional to the concentration of GSH in the voxel of interest, was obtained by frequency-domain spectral fitting as previously described. ${ }^{28}$ The derived GSH peak areas were then expressed semiquantitatively as ratios relative to the unsuppressed intravoxel water signal for normalization across subjects before being used in group analyses. To estimate the proportions of gray matter, white matter, and CSF contained in the voxel of interest, the volumetric spoiled gradient-recalled echo MR imaging data were segmented by using Statistical Parametric Mapping software (SPM8; http://www.fil.ion.ucl.ac.uk/spm/software/spm8).

\section{Pittsburgh Compound-B PET Image Acquisition and Analysis}

All subjects underwent an amyloid PET scanning on a Biograph PET-CT scanner (Siemens, Erlangen, Germany; 1-mm full width at half maximum, 25-cm FOV) by using a standardized research protocol. ${ }^{17}$ All subjects received an intravenous catheter for injection of $15 \mathrm{mCi}$ of PiB. Sixty minutes after injection, subjects were scanned for 30 minutes with their eyes open in a quiet, dimly lit room. A low-dose CT scan was acquired for attenuation correction, and all images were reconstructed into a $512 \times 512$ matrix.

Summed PET images corresponding to the 60-90 minutes of $\mathrm{PiB}$ data were generated and nonlinearly normalized to a PiB template. The PiB template was generated by averaging the summed images of 48 cognitively healthy individuals in the same age range, which were downloaded from the Alzheimer's Disease Neuroimaging Initiative (ADNI) on-line data repository (adni.loni. usc.edu). The ADNI was launched in 2003 as a public-private partnership, led by Principal Investigator Michael W. Weiner, $\mathrm{MD}$, with the primary goal of testing whether serial MR imaging, positron-emission tomography, other biologic markers, and clinical and neuropsychological assessment may be combined to measure the progression of mild cognitive impairment and early Alzheimer disease. More information may be obtained at www. adni-info.org.

Orientation and origin for all the PiB PET images were automatically fixed to the anterior commissure to match the templates used in Statistical Parametric Mapping (SPM; Wellcome Department of Imaging Neuroscience, London, UK), because the "normal- ize" function of SPM uses the origin as a starting estimate. These reoriented PiB PET images and the mean PiB template were skullstripped with the FSL Brain Extraction Tool (http://fsl.fmrib.ox. ac.uk/fsl/fslwiki/BET $)^{34}$ to avoid any bias induced by skull staining. All the skull-stripped PiB PET images were then nonlinearly warped to the skull-stripped mean PiB template. Gray matter regions were parcellated by using the Automated Anatomical Labeling atlas of SPM to obtain 116 automated ROIs. ${ }^{35}$ Regional PiB uptake values were then normalized by the subject's cerebellar reference uptake.

Prior ADNI publications determined that the 4 large regions of the brain that are most useful in measuring the degree of brain amyloidosis are the frontal, anterior/posterior cingulate, lateral parietal, and lateral temporal regions, with the cerebellum as a reference region. ${ }^{36-39}$ Using ROIs from the Automated Anatomical Labeling atlas, we determined amyloid deposition in the frontal region by averaging the uptake values from the bilateral superior frontal, bilateral superior orbital frontal, bilateral middle frontal, bilateral inferior frontal opercular, bilateral inferior frontal triangularis, bilateral supplemental motor, bilateral medial superior frontal, and bilateral middle orbital frontal regions of the brain. The cingulate region included the bilateral anterior, middle, and posterior cingulum regions. The lateral parietal region included the bilateral superior and inferior parietal regions, as well as the precuneus. The lateral temporal region included the bilateral and superior middle temporal regions.

\section{Statistical Analysis}

All statistical analyses were performed in STATA, Version 13 (StataCorp, College Station, Texas).

The potential influence of voxel tissue heterogeneity and brain matter content in the analyses was examined by testing for associations between brain matter proportions in the voxel of interest and both MR spectroscopy measures of GSH levels and PiB PET measures of amyloid levels. We also examined the distribution of brain tissue proportions within our subject cohort to identify outliers.

To assess whether there was an association between GSH and brain amyloidosis, based on uptake on PiB PET, we used ordinary least-squares regression analysis with amyloid levels in each of the 4 brain regions as the outcome variable and GSH as the predictor variable. Because APOE $\varepsilon 4$ carrier status has been shown to be associated with increased brain amyloidosis in the literature, ${ }^{40-43}$ carrier status was included as a covariate to adjust for this confounding factor.

The robustness of any association between GSH and amyloidosis was examined by bootstrapping the original cohort of subjects 1000 times to obtain 95\% confidence intervals. ${ }^{44}$ The effect of a clear outlier (high parietal amyloidosis and low GSH) on the association was examined by performing the analyses both with and without this data point. To assess the effect sizes of our associations, we estimated the correlation coefficients between GSH and amyloidosis, with $<0.1$ indicating a small effect, $0.1-0.5$ indicating a medium effect, and $>0.5$ indicating a large effect. ${ }^{45} \mathrm{We}$ also calculated the partial eta-squared for GSH on the basis of the regression models, ${ }^{46}$ with $<0.06$ indicating a small effect, $0.06-$ 0.14 indicating a medium effect, and $>0.14$ indicating a large effect. ${ }^{47}$ 
Table 1: Results of the regression analyses showing associations between glutathione and regional brain amyloidosis

\begin{tabular}{lcccc}
\hline & \multicolumn{4}{c}{ Regression Coefficients } \\
\cline { 2 - 5 } & $\begin{array}{c}\text { Frontal } \\
\text { Amyloidosis }\end{array}$ & $\begin{array}{c}\text { Cingulate } \\
\text { Amyloidosis }\end{array}$ & $\begin{array}{c}\text { Parietal } \\
\text { Amyloidosis }\end{array}$ & $\begin{array}{c}\text { Temporal } \\
\text { Amyloidosis }\end{array}$ \\
\hline Glutathione levels $( \pm$ SE) & $-39 \pm 90$ & $-27 \pm 174$ & $-308 \pm 143$ & $-209 \pm 85$ \\
$P$ value & .67 & .88 & .05 & .03 \\
\hline
\end{tabular}

Note:-SE indicates standard error.
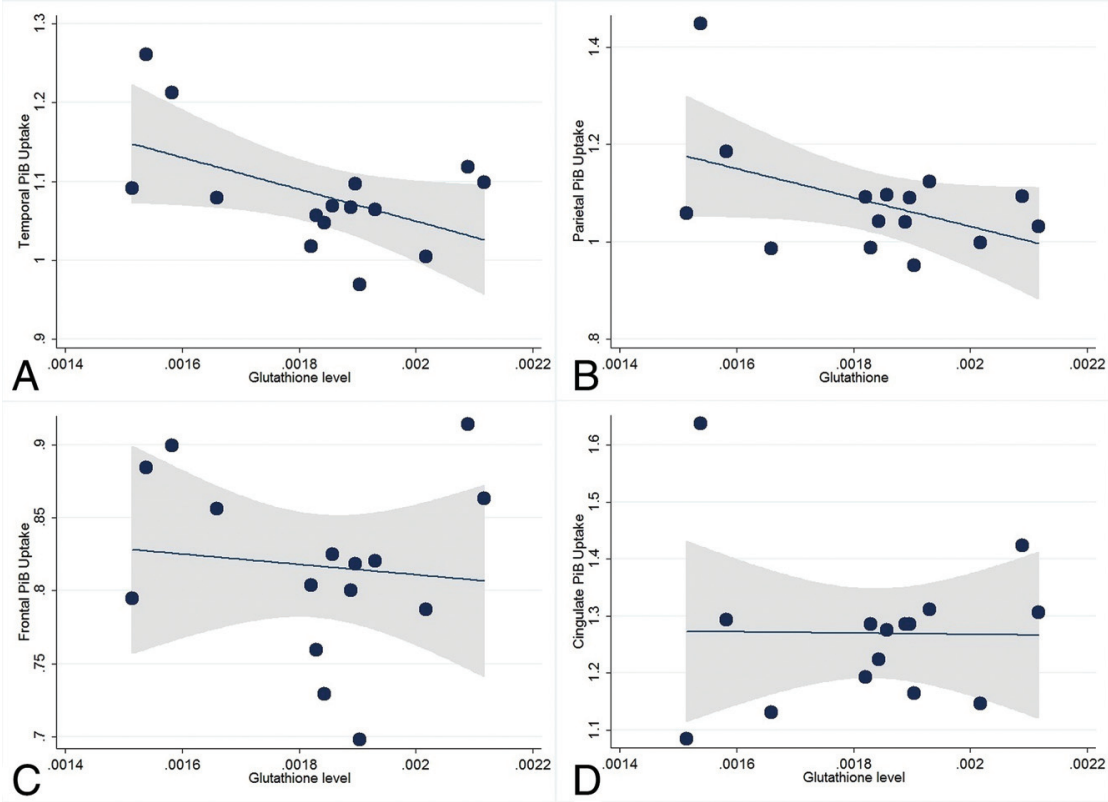

FIG 2. Scatterplots showing the relationship between glutathione levels and brain amyloidosis by region. After we adjusted for $A P O E 4$ carrier status, lower glutathione levels were associated with higher levels of amyloidosis in the temporal $(A)(P=.03)$ and in the parietal $(B)(P=.05)$ regions, but not in the frontal $(C)(P=.67)$ or cingulate $(D)(P=.88)$ regions. Fitted lines and $95 \%$ confidence intervals (shaded area) are also shown.

Table 2: Results of the regression analyses showing associations between glutathione and age-adjusted cognitive scores on the Repeatable Battery for the Assessment of Neuropsychological Status

\begin{tabular}{lccccc}
\hline & \multicolumn{5}{c}{ Regression Coefficients $\left(\times 10^{2}\right)$} \\
\cline { 2 - 6 } & $\begin{array}{c}\text { Immediate } \\
\text { Memory } \\
\text { Subscore }\end{array}$ & $\begin{array}{c}\text { Delayed } \\
\text { Memory } \\
\text { Subscore }\end{array}$ & $\begin{array}{c}\text { Visuospatial/ } \\
\text { Construction } \\
\text { Subscore }\end{array}$ & $\begin{array}{c}\text { Language } \\
\text { Subscore }\end{array}$ & $\begin{array}{c}\text { Attention } \\
\text { Subscore }\end{array}$ \\
\hline Glutathione levels ( \pm SE) & $317 \pm 198$ & $232 \pm 171$ & $113 \pm 183$ & $-24 \pm 242$ & $361 \pm 247$ \\
$P$ value & .14 & .20 & .55 & .92 & .17 \\
\hline
\end{tabular}

Note:-SE indicates standard error.

To assess whether there was an association between GSH levels and memory, we again used ordinary least-squares regression analysis with GSH as the predictor and the age-adjusted subscores from the RBANS as the outcome variable. Because APOE $\varepsilon 4$ carrier status is known to be a risk factor for $\mathrm{AD},{ }^{48,49}$ it was again included as a covariate.

Finally, we explored the associations between GSH and potential mediators of oxidative stress, including obesity, hypercholesterolemia, hypertension, and exercise, again by using ordinary least-squares regression analyses.

\section{RESULTS}

Subjects ranged in age from 55 to 72 years (mean, $63 \pm 5$ years), and $5(33 \%)$ of the subjects were women. All subjects completed at least a year of college, with a mean of $16 \pm 3$ years of education.
Five $(33 \%)$ subjects had a family history of dementia. Ten $(67 \%)$ subjects had the APOE $\varepsilon 3 / \varepsilon 3$ genotype, 2 (13\%) subjects carried the $A P O E \varepsilon 2 / \varepsilon 3$ genotype, and 3 (20\%) subjects had the APOE $\varepsilon 3 / \varepsilon 4$ genotype. Eight (53\%) subjects had comorbid hypercholesterolemia, and 7 (47\%) subjects had comorbid hypertension. Body mass index ranged from 22 to 37 , with a mean of $29 \pm 4$. Subjects reported exercising $0-14$ hours per week, with a mean of $3 \pm 4$ hours.

The results of the regression analyses evaluating the association between ${ }^{1} \mathrm{H}-\mathrm{MR}$ spectroscopy GSH and amyloidosis as assessed by PiB PET are provided in Table 1 and shown in Fig 2. There were no significant associations between tissue proportions and GSH levels or amyloidosis. After we adjusted for APOE $\varepsilon 4$ status, GSH levels were inversely associated with levels of amyloidosis in both the temporal region $(P=.03$, coefficient $=-209 ; 95 \%$ confidence interval, -395 to -23$)$ and parietal region $(P=.05$, coefficient $=$ $-308 ; 95 \%$ confidence interval, -621 to 3). Post hoc bootstrapping yielded a $P$ value of .08 ( $95 \%$ confidence interval, -441 to 23 ) for the temporal region and 0.1 (95\% confidence interval, -705 to 88) for the parietal region. In addition, the association between parietal region amyloidosis and GSH appears to have been primarily driven by 1 subject with high amyloidosis and low GSH. The association was no longer significant when this outlier was excluded (coefficient $=$ $-62, P=.60$ ). There was no significant association between GSH levels and either frontal $(P=.67)$ or cingulate $(P=$ 88) region amyloidosis.

The correlation coefficient between GSH and temporal region amyloidosis was -0.51 , indicating a large effect size. The correlation coefficient between GSH and parietal region amyloidosis was -0.47 , indicating a medium effect size. In the regression models, the effect sizes for GSH were large, explaining a greater proportion of the variance in amyloidosis than in $A P O E \varepsilon 4$ status. The partial eta-squared for GSH and $A P O E \varepsilon 4$ was 0.33 and 0.25 , respectively, for the temporal region. The partial eta-squared for GSH and APOE $\varepsilon 4$ was 0.28 and 0.23 , respectively, for the parietal region.

The results of the regression analyses evaluating the association between GSH and cognition are provided in Table 2 and shown in Fig 3. None of the associations were statistically significant.

The results of the exploratory regression analyses evaluating

AJNR Am J Neuroradiol 38:1130-37 Jun 2017 www.ajnr.org 1133 

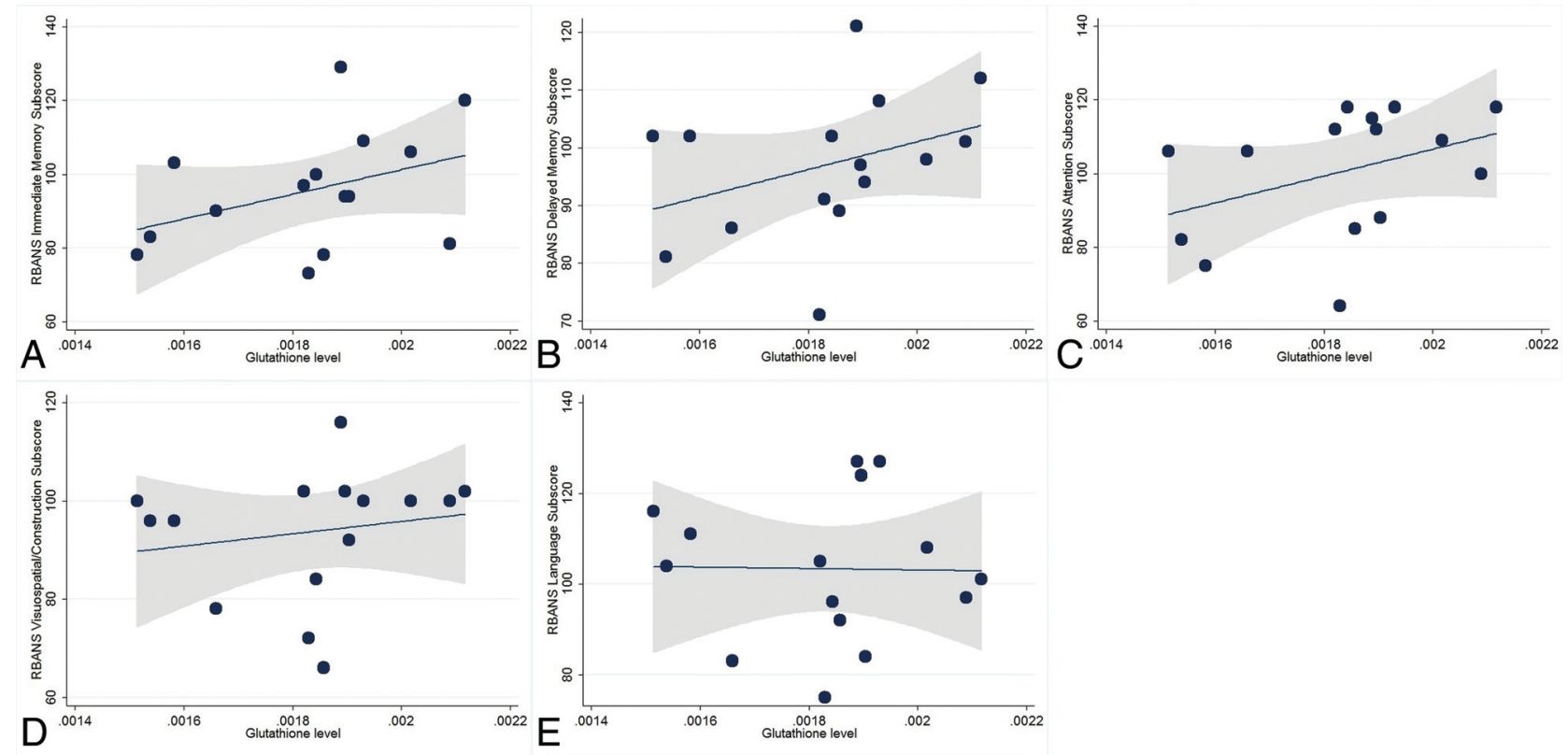

FIG 3. Scatterplots showing the relationship between glutathione levels and scores on the Repeatable Battery for the Assessment of Neuropsychological Status. There were no significant associations between higher glutathione levels and higher age-adjusted immediate $(A)(P=.14)$ and delayed $(B)(P=.20)$ memory subscores. Higher glutathione levels were not associated with attention $(C)(P=.17)$, visuospatial/construction $(D)(P=.55)$, or language $(E)(P=.92)$ subscores. Fitted lines and $95 \%$ confidence intervals (shaded area) are also shown.

Table 3: Association between Alzheimer risk factors and glutathione levels

\begin{tabular}{lcccc}
\hline & \multicolumn{4}{c}{ Regression Coefficients $\left(\times 10^{-5}\right)$} \\
\cline { 2 - 5 } & $\begin{array}{c}\text { Body } \\
\text { Mass Index }\end{array}$ & $\begin{array}{c}\text { Exercise } \\
\text { (hr per wk) }\end{array}$ & $\begin{array}{c}\text { Comorbid } \\
\text { Hypertension }\end{array}$ & $\begin{array}{c}\text { Comorbid } \\
\text { Hypercholesterolemia }\end{array}$ \\
\hline Glutathione levels $( \pm \mathrm{SE})$ & $-2.2 \pm 1.23$ & $-1.3 \pm 1.4$ & $-5.5 \pm 9.9$ & $-8.4 \pm 11.0$ \\
$P$ value & .08 & .36 & .59 & .46 \\
\hline
\end{tabular}

Note:-SE indicates standard error.

the association between GSH levels and risk factors for AD are shown in Table 3. There was a trend-level inverse association between body mass index and GSH levels $(P=.08)$. Exercise, hypercholesterolemia, and hypertension were not significantly associated with GSH levels $(P>.05)$.

\section{DISCUSSION}

The value of noninvasive measurement of GSH by ${ }^{1} \mathrm{H}-\mathrm{MR}$ spectroscopy lies in its potential to directly implicate and support a role for oxidative stress in the early stages of $\mathrm{AD}$ development. Using this technique, the present study sought to identify a role for oxidative stress in a prospective cohort of healthy older subjects, assessing potential associations between cortical GSH levels and brain amyloidosis and between GSH and memory. The major finding was that GSH levels, measured with ${ }^{1} \mathrm{H}-\mathrm{MR}$ spectroscopy, are negatively associated with brain amyloidosis, as assessed with $\mathrm{PiB}$ PET, in the temporal and parietal regions. In this cognitively healthy cohort, there were no associations between GSH levels and immediate and delayed memory.

The inverse association between levels of GSH and temporal and parietal amyloid levels supports a role for oxidative stress in amyloid plaque formation - a finding that is consistent with prior laboratory and preclinical studies. ${ }^{5,6-8,46-49}$ An association between oxidative stress and amyloidosis has also been suggested by clinical studies on AD. Mandal et $\mathrm{al}^{50}$ found that GSH levels measured by ${ }^{1} \mathrm{H}-\mathrm{MR}$ spectroscopy could accurately discriminate among healthy subjects, individuals with mild cognitive impairment, and patients with $\mathrm{AD}$, with decreased GSH levels being associated with increased levels of cognitive impairment. In postmortem $\mathrm{AD}$ brains, ${ }^{51}$ depleted GSH levels accompanied the diagnosis of $\mathrm{AD}$. There have also been reports associating GSH depletion with mitochondrial dysfunction ${ }^{52,53}$ and neuronal degeneration. ${ }^{54,55}$ On the other hand, increased GSH levels have been reported in those with mild cognitive impairment compared with healthy subjects, suggesting that there may be a compensatory up-regulation of GSH in the early stages of AD. ${ }^{56}$ However, no direct relationship between oxidative stress and amyloidosis was established in any of the prior clinical studies because subject groups were defined clinically without quantifying the degree of underlying amyloidosis. In the present study, with an advanced ${ }^{1} \mathrm{H}-\mathrm{MR}$ spectroscopy editing technique that enables reliable in vivo measurements of GSH, we have obtained strong preliminary evidence of an inverse relationship between GSH levels and amyloidosis in older adults, even before the onset of mild cognitive impairment. Replication in larger cohorts would both solidify this result and support measurement of brain GSH levels with ${ }^{1} \mathrm{H}-\mathrm{MR}$ spectroscopy as a noninvasive biomarker of AD risk early in disease development.

This study also investigated whether GSH levels are associated with memory because memory deficits are known to be the earliest clinical manifestation of $\mathrm{AD}^{57}$ and predict time-to-progression from cognitively healthy to mild cognitive impairment. ${ }^{58}$ Because oxidative stress can exert deleterious effects on mitochondrial function and neuronal integrity, we surmised that GSH depletion could also lead to memory dysfunction. Two prior studies that included subjects with mild cognitive impairment and AD 
reported conflicting results, with one reporting GSH deficits in mild cognitive impairment and $\mathrm{AD}^{50}$ and the other reporting a potential compensatory increase of GSH in mild cognitive impairment. ${ }^{56}$ Our study found no associations between GSH levels and cognitive scores in our cognitively healthy cohort, necessitating further studies in larger cohorts.

In exploring associations between GSH and AD risk factors, we found a trend-level inverse association between GSH levels and body mass index. Barnes and Yaffe ${ }^{15}$ previously reported that up to $54 \%$ of $\mathrm{AD}$ cases may be attributable to modifiable risk factors, with $21 \%$ attributable to physical inactivity and $7 \%$ attributable to obesity. In the present cohort, we explored the association between these risk factors and GSH levels and found a trendlevel negative association with body mass index, which could be consistent with a prior large cohort study of $>2000$ subjects, which found increased markers of oxidative stress, which would deplete GSH, with increased body mass index. ${ }^{59}$ If this finding is validated, monitoring GSH levels by ${ }^{1} \mathrm{H}$-MR spectroscopy could also serve as a biomarker of the potential benefits of various lifestyle-modification regimens, without the radiation risk and cost of PET imaging.

Finally, this study has a number of limitations. First, the sample size was relatively small, potentially limiting both statistical power and generalizability of the findings. Replication of these findings in larger cohorts will be necessary. Second, our cohort consisted of cognitively healthy individuals. As a result, subjects did not have significant memory deficits, possibly limiting our ability to detect statistically significant associations between GSH and memory, particularly in a small cohort. Third, we targeted the precuneus for GSH measurement with MR spectroscopy because this region is affected early in $\mathrm{AD}$ pathology. However, there may be abnormalities in other brain regions, which would need to be investigated to obtain a more complete understanding of oxidative stress-associated brain damage in $\mathrm{AD}$ and its prodromal stages. Furthermore, although we found associations between GSH and amyloidosis, longitudinal studies are necessary to determine whether decreased GSH levels increase subsequent risk of developing AD. Finally, we did not enroll a control group for comparison with our cognitively healthy cohort. As a result, it is not known whether the GSH levels detected in our cohort are significantly abnormal.

\section{CONCLUSIONS}

This is the first study, to our knowledge, to explore in vivo associations between GSH and brain amyloidosis, as well as GSH and memory in a cognitively healthy cohort. This supports a role for ${ }^{1} \mathrm{H}-\mathrm{MR}$ spectroscopy measures of cortical glutathione as a potential early biomarker of $\mathrm{AD}$ pathology and therapeutic response monitoring of existing or future disease-modifying interventions targeting oxidative stress.

\section{ACKNOWLEDGMENTS}

We are grateful to Dr Amy Kuceyeski for assistance with the imaging atlas creation and analysis.

Data collection and sharing for this project were funded by the Alzheimer's Disease Neuroimaging Initiative (National Institutes of Health Grant U01 AG024904) and Department of Defense
ADNI (Department of Defense award number W81XWH-12-20012). ADNI is funded by the National Institute on Aging, the National Institute of Biomedical Imaging and Bioengineering, and through generous contributions from the following: AbbVie; Alzheimer's Association; Alzheimer's Drug Discovery Foundation; Araclon Biotech; BioClinica; Biogen; Bristol-Myers Squibb Company; CereSpir; Cogstate; Eisai; Elan Pharmaceuticals; Eli Lilly and Company; Euroimmun; F. Hoffmann-La Roche Ltd and its affiliated company Genentech; Fujirebio; GE Healthcare; IXICO Ltd; Janssen Alzheimer Immunotherapy Research \& Development, LLC; Johnson \& Johnson Pharmaceutical Research \& Development LLC; Lumosity; Lundbeck; Merck \& Co; Meso Scale Diagnostics LLC; NeuroRx Research; Neurotrack Technologies; Novartis Pharmaceuticals Corporation; Pfizer; Piramal Imaging; Servier; Takeda Pharmaceutical Company; and Transition Therapeutics. The Canadian Institutes of Health Research is providing funds to support ADNI clinical sites in Canada. Private sector contributions are facilitated by the Foundation for the National Institutes of Health (www.fnih.org). The grantee organization is the Northern California Institute for Research and Education, and the study is coordinated by the Alzheimer's Therapeutic Research Institute at the University of Southern California. ADNI data are disseminated by the Laboratory for Neuro Imaging at the University of Southern California.

Data used in preparation of this article were obtained from the Alzheimer's Disease Neuroimaging Initiative database (adni.loni. usc.edu). Thus, the investigators within the ADNI contributed to the design and implementation of ADNI and/or provided data but did not participate in analysis or writing of this report. A complete listing of ADNI investigators can be found at http:// adni.loni.usc.edu/wp-content/uploads/how_to_apply/ADNI_ Acknowledgement_List.pdf.

Disclosures: Eileen Chang_-RELATED: Grant: Clinical and Translational Science Center, Comments: Clinical and Translational Science Center/National Center for Advancing Translational Sciences UL1 RR024996. * Lisa D. Ravdin-UNRELATED: Board Membership: Biomedical Research Alliance of New York, Comments: institutional review board work. Dikoma C. Shungu-UNRELATED: Grants/Grants Pending: National Institutes of Health, Department of Defense, Comments: I had a number of regular/standard R-type grants funded by the federal government. * Money paid to the institution.

\section{REFERENCES}

1. Alzheimer's Association. 2016 Alzheimer's disease facts and figures. http://www.alz.org/facts/. Accessed May 29, 2016

2. Mangialasche F, Solomon A, Winblad B, et al. Alzheimer's disease: clinical trials and drug development. Lancet Neurol 2010;9:702-16 CrossRef Medline

3. Apelt J, Bigl M, Wunderlich $\mathrm{P}$, et al. Aging-related increase in oxidative stress correlates with developmental pattern of beta-secretase activity and beta-amyloid plaque formation in transgenic $\operatorname{Tg} 2576$ mice with Alzheimer-like pathology. Int J Dev Neurosci 2004;22: 475-84 CrossRef Medline

4. Nunomura A, Perry G, Aliev G, et al. Oxidative damage is the earliest event in Alzheimer disease. J Neuropathol Exp Neurol 2001;60: 759-67 CrossRef Medline

5. Praticò D, Uryu K, Leight S, et al. Increased lipid peroxidation precedes amyloid plaque formation in an animal model of Alzheimer amyloidosis. J Neurosci 2001;21:4183-87 Medline

6. Komatsu H, Liu L, Murray IV, et al. A mechanistic link between oxidative stress and membrane mediated amyloidogenesis revealed

AJNR Am J Neuroradiol 38:1130-37 Jun 2017 www.ajnr.org

1135 
by infrared spectroscopy. Biochim Biophys Acta 2007;1768:1913-22 CrossRef Medline

7. Nunomura A, Castellani RJ, Zhu X, et al. Involvement of oxidative stress in Alzheimer disease. J Neuropathol Exp Neurol 2006;65: 631-41 CrossRef Medline

8. Bonda DJ, Wang X, Lee HG, et al. Neuronal failure in Alzheimer's disease: a view through the oxidative stress looking-glass. Neurosci Bull 2014;30:243-52 CrossRef Medline

9. Pocernich $\mathrm{CB}$, Butterfield DA. Elevation of glutathione as a therapeutic strategy in Alzheimer disease. Biochim Biophys Acta 2012; 1822:625-30 CrossRef Medline

10. Resende R, Moreira PI, Proença T, et al. Brain oxidative stress in a triple-transgenic mouse model of Alzheimer disease. Free Radic Biol Med 2008;44:2051-57 CrossRef Medline

11. Zhang C, Rodriguez C, Spaulding J, et al. Age-dependent and tissuerelated glutathione redox status in a mouse model of Alzheimer's disease. J Alzheimers Dis 2012;28:655-66 CrossRef Medline

12. Hensley K, Carney JM, Mattson MP, et al. A model for beta-amyloid aggregation and neurotoxicity based on free radical generation by the peptide: relevance to Alzheimer disease. Proc Natl Acad Sci US A 1994;91:3270-74 CrossRef Medline

13. Smith MA, Casadesus G, Joseph JA, et al. Amyloid-beta and tau serve antioxidant functions in the aging and Alzheimer brain. Free Radic Biol Med 2002;33:1194-99 CrossRef Medline

14. Rowe CC, Villemagne VL. Brain amyloid imaging. J Nucl Med 2011; 52:1733-40 CrossRef Medline

15. Barnes DE, Yaffe K. The projected effect of risk factor reduction on Alzheimer's disease prevalence. Lancet Neurol 2011;10:819-28 CrossRef Medline

16. Sato N, Morishita R. The roles of lipid and glucose metabolism in modulation of $\boldsymbol{\beta}$-amyloid, tau, and neurodegeneration in the pathogenesis of Alzheimer disease. Front Aging Neurosci 2015;7:199 CrossRef Medline

17. Mosconi L, Rinne JO, Tsui WH, et al. Increased fibrillar amyloid- $\boldsymbol{\beta}$ burden in normal individuals with a family history of late-onset Alzheimer's. Proc Natl Acad Sci U S A 2010;107:5949-54 CrossRef Medline

18. Lasa L, Ayuso-Mateos JL, Vázquez-Barquero JL, et al. The use of the Beck Depression Inventory to screen for depression in the general population: a preliminary analysis. J Affect Disord 2000;57:261-65 CrossRef Medline

19. Beck AT, Epstein N, Brown G, et al. An inventory for measuring clinical anxiety: psychometric properties. J Consult Clin Psychol 1988;56:893-97 CrossRef Medline

20. Randolph C, Tierney MC, Mohr E, et al. The Repeatable Battery for the Assessment of Neuropsychological Status (RBANS): preliminary clinical validity. J Clin Exp Neuropsychol 1998;20:310-19 CrossRef Medline

21. Karantzoulis S, Novitski J, Gold M, et al. The Repeatable Battery for the Assessment of Neuropsychological Status (RBANS): utility in detection and characterization of mild cognitive impairment due to Alzheimer's disease. Arch Clin Neuropsychol 2013;28:837-44 CrossRef Medline

22. Saykin AJ, Shen L, Foroud TM, et al; Alzheimer's Disease Neuroimaging Initiative. Alzheimer's Disease Neuroimaging Initiative biomarkers as quantitative phenotypes: genetics core aims, progress, and plans. Alzheimers Dement 2010;6:265-73 CrossRef Medline

23. Herholz K, Salmon E, Perani D, et al. Discrimination between Alzheimer dementia and controls by automated analysis of multicenter FDG PET. Neuroimage 2002;17:302-16 CrossRef Medline

24. Vogt BA, Vogt LJ, Vrana KE, et al. Multivariate analysis of laminar patterns of neurodegeneration in posterior cingulate cortex in $\mathrm{Alz}$ heimer's disease. Exp Neurol 1998;153:8-22 CrossRef Medline

25. Murray ME, Przybelski SA, Lesnick TG, et al. Early Alzheimer's disease neuropathology detected by proton MR spectroscopy. J Neurosci 2014;34:16247-55 CrossRef Medline

26. Kantarci K. $1 \mathrm{H}$ magnetic resonance spectroscopy in dementia. $\mathrm{Br} \mathrm{J}$ Radiol 2007;80:S146-52 CrossRef Medline
27. Shungu DC, Weiduschat N, Murrough JW, et al. Increased ventricular lactate in chronic fatigue syndrome, III: relationships to cortical glutathione and clinical symptoms implicate oxidative stress in disorder pathophysiology. NMR Biomed 2012;25:1073-87 CrossRef Medline

28. Weiduschat N, Mao X, Hupf J, et al. Motor cortex glutathione deficit in ALS measured in vivo with the J-editing technique. Neurosci Lett 2014;570:102-07 CrossRef Medline

29. Geramita M, van der Veen JW, Barnett AS, et al. Reproducibility of prefrontal $\boldsymbol{\gamma}$-aminobutyric acid measurements with J-edited spectroscopy. NMR Biomed 2011;24:1089-98 CrossRef Medline

30. Mullins PG, McGonigle DJ, O'Gorman RL, et al. Current practice in the use of MEGA-PRESS spectroscopy for the detection of GABA. Neuroimage 2014;86:43-52 CrossRef Medline

31. An L, Zhang Y, Thomasson DM, et al. Measurement of glutathione in normal volunteers and stroke patients at $3 \mathrm{~T}$ using J-difference spectroscopy with minimized subtraction errors. J Magn Reson Imaging 2009;30:263-70 CrossRef Medline

32. Nepravishta R, Sabelli R, Iorio E, et al. Oxidative species and S-glutathionyl conjugates in the apoptosis induction by allyl thiosulfate. FEBS J 2012;279:154-67 CrossRef Medline

33. Shungu DC, Mao X, Gonzales R, et al. Brain $\gamma$-aminobutyric acid (GABA) detection in vivo with the J-editing (1) H MRS technique: a comprehensive methodological evaluation of sensitivity enhancement, macromolecule contamination and test-retest reliability. NMR Biomed 2016;29:932-42 CrossRef Medline

34. Smith SM. Fast robust automated brain extraction. Hum Brain Mapp 2002;17:143-55 CrossRef Medline

35. Tzourio-Mazoyer N, Landeau B, Papathanassiou D, et al. Automated anatomical labeling of activations in SPM using a macroscopic anatomical parcellation of the MNI MRI single-subject brain. Neuroimage 2002;15:273-89 CrossRef Medline

36. Mormino EC, Kluth JT, Madison CM, et al; Alzheimer's Disease Neuroimaging Initiative. Episodic memory loss is related to hippocampal-mediated beta-amyloid deposition in elderly subjects. Brain 2009;132(pt 5):1310-23 CrossRef Medline

37. Jagust WJ, Landau SM, Shaw LM, et al; Alzheimer's Disease Neuroimaging Initiative. Relationships between biomarkers in aging and dementia. Neurology 2009;73:1193-99 CrossRef Medline

38. Landau SM, Breault C, Joshi AD, et al; Alzheimer's Disease Neuroimaging Initiative. Amyloid- $\beta$ imaging with Pittsburgh compound B and florbetapir: comparing radiotracers and quantification methods. J Nucl Med 2013;54:70-77 CrossRef Medline

39. Jagust WJ, Landau SM, Koeppe RA, et al. The Alzheimer's Disease Neuroimaging Initiative 2 PET Core: 2015. Alzheimers Dement 2015; 11:757-71 CrossRef Medline

40. Schmechel DE, Saunders AM, Strittmatter WJ, et al. Increased amyloid beta-peptide deposition in cerebral cortex as a consequence of apolipoprotein $\mathrm{E}$ genotype in late-onset Alzheimer disease. Proc Natl Acad Sci U S A 1993;90:9649-53 CrossRef Medline

41. Reiman EM, Chen K, Liu X, et al. Fibrillar amyloid-beta burden in cognitively normal people at 3 levels of genetic risk for Alzheimer's disease. Proc Natl Acad Sci U S A 2009;106:6820-25 CrossRef Medline

42. Bu G. Apolipoprotein E and its receptors in Alzheimer's disease: pathways, pathogenesis and therapy. Nat Rev Neurosci 2009;10: 333-44 CrossRef Medline

43. Small GW, Siddarth P, Burggren AC, et al. Influence of cognitive status, age, and APOE-4 genetic risk on brain FDDNP positronemission tomography imaging in persons without dementia. Arch Gen Psychiatry 2009;66:81-87 CrossRef Medline

44. Vittinghoff E, Shiboski S, Glidden D, et al. Regression Methods in Biostatistics: Linear, Logistic, Survival, and Repeated Measures Models. New York: Springer-Science and Business Media; 2005;62:138-39

45. Cohen J. A power primer. Psychol Bull 1992;112:155-59 Medline

46. How can I compute effect size in Stata for regression? UCLA: Institute for Digital Research and Education. http://www.ats.ucla.edu/stat/ stata/faq/regeffectsize.htm. Accessed December 15, 2016 
47. Cohen JW. Statistical Power Analysis for the Behavioral Sciences. 2nd ed. Hillsdale: Lawrence Erlbaum Associates; 1988

48. Corder EH, Saunders AM, Strittmatter WJ, et al. Gene dose of apolipoprotein $\mathrm{E}$ type 4 allele and the risk of Alzheimer's disease in late onset families. Science 1993;261:921-23 CrossRef Medline

49. Seshadri S, Drachman DA, Lippa CF. Apolipoprotein E epsilon 4 allele and the lifetime risk of Alzheimer's disease: what physicians know, and what they should know. Arch Neurol 1995;52:1074-79 CrossRef Medline

50. Mandal PK, Saharan S, Tripathi M, et al. Brain glutathione levels-a novel biomarker for mild cognitive impairment and Alzheimer's disease. Biol Psychiatry 2015;78:702-10 CrossRef Medline

51. Gu M, Owen AD, Toffa SE, et al. Mitochondrial function, GSH and iron in neurodegeneration and Lewy body diseases. J Neurol Sci 1998;158:24-29 CrossRef Medline

52. Jain A, Mårtensson J, Stole E, et al. Glutathione deficiency leads to mitochondrial damage in brain. Proc Natl Acad Sci U S A 1991;88: 1913-17 CrossRef Medline

53. Venkateshappa C, Harish G, Mahadevan A, et al. Elevated oxidative stress and decreased antioxidant function in the human hippocampus and frontal cortex with increasing age: implications for neuro- degeneration in Alzheimer's disease. Neurochem Res 2012;37: 1601-14 CrossRef Medline

54. Gibson GE, Starkov A, Blass JP, et al. Cause and consequence: mitochondrial dysfunction initiates and propagates neuronal dysfunction, neuronal death and behavioral abnormalities in age-associated neurodegenerative diseases. Biochim Biophys Acta 2010;1802: 122-34 CrossRef Medline

55. Lin MT, Beal MF. Mitochondrial dysfunction and oxidative stress in neurodegenerative diseases. Nature 2006;443:787-95 CrossRef Medline

56. Duffy SL, Lagopoulos J, Hickie IB, et al. Glutathione relates to neuropsychological functioning in mild cognitive impairment. Alzheimers Dement 2014;10:67-75 CrossRef Medline

57. Lezak MD, Howieson D, Loring D. Neuropsychological Assessment, 4th ed. Oxford: Oxford University Press; 2004:207-15

58. Blacker D, Lee H, Muzikansky A, et al. Neuropsychological measures in normal individuals that predict subsequent cognitive decline. Arch Neurol 2007;64:862-71 CrossRef Medline

59. Wonisch W, Falk A, Sundl I, et al. Oxidative stress increases continuously with BMI and age with unfavourable profiles in males. Aging Male 2012;15:159-65 CrossRef Medline 